\title{
Transformation of gender characteristics women teachers in the process of professional activities
}

\author{
R.R. Khalfina ${ }^{1 *}, I . R . \mathrm{Khokh}^{2}$, and O.N. Khakhlova ${ }^{3}$ \\ ${ }^{1}$ Bashkir State University, Ufa, Russia \\ ${ }^{2}$ Bashkir State University, Ufa, Russia \\ ${ }^{3}$ Bashkir State University, Ufa, Russia
}

\begin{abstract}
The teaching profession is one of the oldest professions on earth. The role of the teacher was performed only by smart and talented people, who from time immemorial were only men. The teacher at all times had an important task, which was to educate a worthy younger generation and transfer the accumulated experience to it. Currently, there is a feminization of education, that is, the role of a teacher is performed mainly by women, mainly feminine. The very same pedagogical activity "requires" from a specialist such qualities as dedication, energy and the ability to lead, which are traditionally male. Under the influence of professional requirements, the personality of the employee changes, which entails his deformation, which also leads to a decrease in the efficiency of labor activity and disturbances in everyday life. Many authors are of the opinion that the whole personality is characterized not by masculinity or femininity, but by androgyny. It is understood as the unification of the female emotionalexpressive style and the male instrumental style of activity, freedom of bodily expressions and preferences from the rigid dictate of gender roles. Such a personality is considered to be more adaptive. In the course of our research, we found that feminine teachers prevail among modern women educators. In the group with more than 26 years of teaching experience there are more of them than in the other two groups, while in the group with 16 to 25 years of experience they are the least. Masculinity is observed only in the group with experience from 0 to 15 years, and then in a small amount. The number of androgynous female teachers is predominant in all three groups.
\end{abstract}

\section{A problem statement}

In modern education, women prevail, and males are much less represented. This is partly due to the fact that the teaching profession is low-paid and not prestigious. But, one way or another, in modern society we are witnessing the feminization of education [1-6].

However, the fact that teachers for centuries have been men has not passed without a trace. This is manifested, first of all, in the fact that pedagogical activity itself "requires"

${ }^{*}$ Corresponding author: ipcs-profped@yandex.ru 
from the employee such qualities as the ability to lead, purposefulness, energy and ability to lead, which are traditionally considered masculine [7-9].

Like any profession, pedagogical activity leaves its "imprint" on the personality of a specialist. Very often, a teacher who has worked for many years has excessive sociability, a desire to teach people to live "correctly" and organize their activities. This is a manifestation of deformation and affects professional activities and daily life in general. In addition, often the teacher has a syndrome of emotional burnout, which entails changes in all spheres of his life (both professional and everyday) [10-12].

Changes in personal characteristics in connection with work experience were studied by S.P. Beznosov, G.A. Vinogradova, R.M. Granovskaya, E.P. Ilyin, S.V. Kondratyeva, A.V. Osnitsky, M.S. Ponomareva, E.I. Rogov, T.G. Syritso, T.V. Formanyuk and others.

Many authors have conducted studies concerning the representation of masculine and feminine students or workers in a particular field (S.V. Afinogenova, A.V. Morozov, V.M. Pogolsha, V.A. Poryadina, O.M. Razumnikov). In this case, only a quantitative indicator of these characteristics was studied [13-15].

However, in the currently existing literature there are no data concerning the study of changes in gender characteristics in the process of increasing the length of service of a specialist, including a teacher. This circumstance made it possible to formulate the problem of this study.

\subsection{The objective of the work}

Purpose of the study: study of the transformation of gender characteristics of women teachers in the process of their professional activities.

Research objectives:

1. To highlight the features of gender characteristics of women teachers.

2. To investigate the transformation of gender characteristics of women teachers in the process of professional activity.

3. To study the level of emotional burnout of teachers with different length of service as one of the reasons for the transformation of gender characteristics.

\section{Materials and the results of the research}

Empirical base and sample of the study: the study was carried out on the basis of the secondary school № 9 g... Ufa. The study involved 60 female teachers with different teaching experience, according to which the subjects were divided into three groups (from 0 to 15 years old, from 16 to 25 years old, from 26 years old and more).

The aim of the empirical research is to study the transformation of gender characteristics in women teachers in the course of their professional activities.

The study was conducted on the basis of a secondary school in Ufa from September 2015 to March 2018. It was attended by 60 women teachers who are employees of one educational institution. All subjects, depending on the length of service, were divided into 3 groups:

1) experience from 0 to 15 years,

2) work experience from 16 to 25 years,

3) work experience of 26 years or more.

Empirical: psychodiagnostic method.

To test the hypothesis, the following techniques were used in the work:

1. The Masculinity-Femininity Scale from the Freiburg Personality Questionnaire (FPI) (E.P. Ilyin, 2010);

2. Methodology "Masculinity-Femininity" S. Boehm; 
3. "Twenty Statements" by M. Kuhn and T. McPartland;

4. V.V. Boyko's method of diagnosing the level of emotional burnout;

5. Self-attitude test questionnaire (V.V. Stolin, S.R. Panteleev).

At the first stage of the study we determined gender characteristics of women teachers in three groups, depending on the length of service.

The study was carried out using the following methods: (FPI),

- the scale "Masculinity-femininity" from the Freiburg Personality Questionnaire

- methodology "Masculinity-femininity" S. Boehm,

The diagnostic results according to the methods are presented in table 1 .

From the table and the histogram, we see that masculinity is observed only in the first group of subjects with experience from 0 to 15 years, and it is expressed insignificantly.

Femininity is equally expressed among teachers with more than 25 years of experience $(25 \%)$ and among novice teachers $(25 \%)$.

Table 1. The severity of masculinity - femininity among women teachers with different experience in teaching (\%).

\begin{tabular}{|c|c|c|c|c|c|}
\hline \multirow[b]{2}{*}{ Experience } & \multicolumn{3}{|c|}{$\begin{array}{l}\text { Methodology "Masculinity-Femininity" } \\
\text { S. Boehm }\end{array}$} & \multicolumn{2}{|c|}{$\begin{array}{ll}\text { FPI } & \text { Masculinity-Femininity } \\
\text { Scale } & \end{array}$} \\
\hline & Masculinity & Androgyny & Femininity & Masculinity & Femininity \\
\hline $0-15$ & five & 70 & 25 & 55 & 45 \\
\hline $16-25$ & 0 & 85 & 15 & 55 & 45 \\
\hline $\begin{array}{l}26 \text { and } \\
\text { more }\end{array}$ & 0 & 75 & 25 & thirty & 70 \\
\hline
\end{tabular}

Femininity is least of all expressed among teachers with a pedagogical experience of 16 to 25 years $(15 \%)$.

Thus, the number of teachers with pronounced feminine traits is the most at the initial stages of their careers and at the stage of achieving mastery.

It should also be noted that in all three groups the overwhelming majority of women teachers are of the androgynous type, that is, their behavior is characterized by both male and female traits. This type is most pronounced among teachers in the middle of their careers $(85 \%)$.

Thus, we can conclude that the teachers of each of the three groups are dominated by androgyny, that is, masculine and feminine traits are expressed harmoniously and equally.

Additionally, the gender characteristics of women teachers were studied using the Masculinity-Femininity scale from the FPI questionnaire.

Analyzing this histogram, we see that in the first two groups, teachers with masculine features are most pronounced. They are decisive, energetic, independent and active. In the third group, where there are subjects with more than 26 years of experience, female teachers with feminine traits prevail. We can say about them that they are soft, calm, capable of compassion and empathy.

If we compare the data on the methodology "Masculinity-Femininity" by S. Boehm and the scale "Masculinity-Femininity" of the Freiburg Personality Questionnaire (FPI), then one can notice the discrepancy between the results. Thus, one of them indicates a large number of masculine women teachers in the first and second groups, while the other shows the opposite trend. According to her, masculine female teachers are observed only in the first group, and then to a minimal extent.

This discrepancy may be due to the fact that in the method we used (the scale "masculinity-femininity" of the Freiburg personality questionnaire - FPI) the boundaries between masculinity and femininity are not strictly delineated, and also in this test, androgyny (presence of male and female qualities) ... 
Further, in our opinion, it will be interesting to see which of the qualities presented in the methodology "Masculinity-Femininity" by S. Bem are most pronounced in representatives of each of the three groups.

Analyzing the data presented in it, we see that the teachers in all three groups clearly expressed such qualities as the ability to yield, self-confidence, tenderness, femininity and devotion. They are reliable, cheerful, helpful, empathic, tactful. Teachers tend to take care of people, understand and sympathize with them, are able to comfort, know how to be friends and love children.

The presence of all these qualities is a good indicator, because the success of a teacher's professional activity largely depends on them. It should be noted that most of the above qualities are female traits.

In the second stage of the study we determined the features of the personal identity and self-attitude of women teachers at different stages of professional activity.

To determine the socially significant roles of women teachers, we used the methodology "Twenty Statements" by M. Kuhn and T. McPartland.

Analyzing the data obtained, we see that for the subjects of the first group with work experience from 0 to 15 years, the most important category is "other" (90\%), that is, leisure, rest, taking care of their own health and communication. Family is important for $5 \%$ of respondents in this group. Family (30\%) and profession (20\%) are in second place for this group of respondents. Family and profession are equally important for $15 \%$ of the subjects.

In the second group (work experience from 16 to 25 years) for the majority of respondents (95\%), the most important are rest, leisure, travel, that is, the category "other", for 5\% - family. In second place in importance for 35\% of the subjects is the family, and for $20 \%$ - the profession.

In the third group (experience of 26 years or more), $85 \%$ of the respondents consider the category "other" to be the most important, which includes rest, leisure, travel. In second place in importance for $70 \%$ is the family, and for $10 \%$ - the profession.

Thus, we can conclude that, regardless of the length of service for women teachers, the profession is among the three most important spheres of life, but it does not take the first place. Moreover, for all three groups of subjects, the family is more important than the profession.

Next, we will consider the features of gender identity (gender aspect) separately for each of the three groups. The data were obtained by the method "Twenty statements" M. Kuhn and T. McPartland.

Analyzing the data presented, we see that the majority of teachers with work experience of up to 15 years have feminine traits $(80 \%)$. The same number of teachers $(10 \%$ each) has neutral and masculine traits.

Analyzing the data obtained, we see that the majority of teachers with work experience from 16 to 25 years have the most pronounced feminine traits $(50 \%), 35 \%$ have neutral traits, and $15 \%$ of respondents have masculine traits.

We also see that the majority of teachers with over 25 years of experience have feminine traits $(65 \%)$. Neutral ones were expressed in $25 \%$ of the subjects, masculine - in $10 \%$.

Thus, teachers with feminine traits predominate in all three groups. Feminine traits are most pronounced in the group of novice teachers (experience from 0 to 15 years). In the second group, femininity is markedly reduced (by 30\%), compared with the first group $(80 \%)$, and in the third, a slight increase is observed $(65 \%)$. These results coincide with the results of diagnostics by the method of S. Boehm.

The "neutrality" indicator is most pronounced in the second group (35\%). With the transition from the second to the third group, a slight decrease in the number of respondents with this characteristic $(25 \%)$ is noticeable. 
An interesting fact is that the number of teachers with masculine traits in the first and third groups is the same.

The formation of the teacher's personality initially occurs in the process of professional activity, and then the personality itself forms this activity. Self-attitude plays an important role in this process, since it is with the help of it that the teacher realizes and evaluates himself as a professional (positively or negatively) and, on the basis of this, interacts with the team and students, plans and builds his pedagogical activity. With a positive attitude towards himself, the teacher will strive to improve it and self-improve in it.

To determine the characteristics of the self-attitude of teachers, at various stages of professional development, we used the self-attitude test questionnaire of V.V. Stolin and S.R. Panteleev.

When analyzing the results obtained for the majority of women teachers with experience from 0 to 15 years, the following was revealed.

$50 \%$ of teachers have high scores on the "self-leadership" scale. This means that people consider themselves to be the main source of activity and results, which relate to both the activity and the subject's personality itself.

$50 \%$ of teachers have high scores on the scale of "self-interest", indicating interest in their own thoughts, feelings, as well as confidence in their "interestingness" for other people.

$30 \%$ of teachers have high scores on the attitude-to-others scale. Such people believe that their personality, character and activities are capable of evoking understanding, sympathy and respect in others.

$30 \%$ of teachers have high scores on the "self-acceptance" scale, which speak of unconditional acceptance of oneself, approval of their plans and desires.

$20 \%$ of teachers have high scores on the "self-blame" scale. Such people tend to see in themselves, mainly, shortcomings, criticize themselves and endure self-reprimands.

$20 \%$ of teachers have high scores on the "self-understanding" scale. Such people are characterized by awareness of their strengths, capabilities and interests, that is, understanding themselves.

$10 \%$ of teachers have high scores on the self-confidence scale; self-image as a strong, strong-willed and energetic person.

At the same time, a number of indicators are not expressed or expressed slightly. Among them are "self-esteem" (60\%), "self-confidence" (70\%), "attitude of others" $(60 \%)$ and "self-accusation" (70\%), since most of them lack these qualities.

Analyzing the data, we see that for the group of respondents with experience in teaching from 16 to 25 years, less characteristic qualities are "self-confidence" (55\%) and "selfaccusation" (55\%), since most of these qualities are absent, and the most pronounced qualities are "self-leadership" (85\%) and "self-interest" (55\%).

In general, we can conclude that this group of teachers has high indicators on the scale of "self-leadership" (85\%), "self-interest" (55\%), "self-acceptance" (45\%), "selfunderstanding" (35\%), "self-blame "(25\%). 10\% of teachers have high scores on the scales of "self-confidence" and "attitude of others".

Analyzing the data, we see that for a group of teachers with more than 26 years of experience, a less characteristic quality is "self-accusation" (70\%), since the majority of respondents do not have this quality, and the most pronounced qualities are "selfconfidence" (55\%), “ self-acceptance "(50\%),“ self-management "(60\%) and" selfunderstanding " $(60 \%)$.

Then we calculated the mean values for all scales separately for each group of teachers. The data are presented in Table 2 . 
Table 2. Average scores on the self-attitude test V.V. Stolin and S.R. Panteleeva.

\begin{tabular}{|ll|l|l|l|}
\hline Scale & $\begin{array}{l}\text { Experience } \\
\text { years }\end{array}$ & $\begin{array}{l}\text { Experience 16-25 } \\
\text { years }\end{array}$ & $\begin{array}{l}\text { Over 26 years } \\
\text { of experience }\end{array}$ \\
\hline 1. & Overconfidence & 41.1 & 59 & 63.7 \\
\hline 2. & Attitude of others & 46.6 & 46.5 & 34.3 \\
\hline 3. & Self-acceptance & 62.9 & 72.6 & 66.7 \\
\hline 4. & Self-guidance & 68.5 & 79.8 & 72.8 \\
\hline 5. & Self-blame & 42.6 & 51.9 & 41.5 \\
\hline 6. & Self-interest & 56.2 & 65.6 & 55.5 \\
\hline 7. & Self-understanding & 59.6 & 62.9 & 77.6 \\
\hline
\end{tabular}

Analysis of the mean values for individual scales showed the following.

According to the "Self-confidence" scale, there is an increase in indicators with an increase in the length of service, which may be associated with both the accumulation of professional skills and the accumulation of life experience by the respondents.

Indicators on the scale "Attitude of others" are low relative to other scales, that is, approval from others is the least significant factor determining the self-attitude of teachers in their professional activities, and by the end of their professional career this indicator decreases even more.

On the scale "Self-acceptance" there is an increase in values by the middle of a professional career (in group 2), and in the third group, it slightly decreases.

In all three groups, "Self-leadership" is clearly expressed, especially among teachers with work experience of 15 to 25 years, that is, they consider themselves the main source of activity and results related to both their activities and the personality itself.

Another clearly expressed characteristic of teachers is "Self-understanding", which grows from group to group, which speaks of the process of personality maturation, awareness of their own strengths and capabilities. This can be explained by the fact that the teacher at this stage has already realized himself as a professional and has a great store of knowledge and professional experience, and also has a clear idea of the profession and his place in it.

"Self-interest" is most pronounced in the middle of a professional career, and "Selfblame", expressed insignificantly on the whole, is most represented in the middle of a career.

Thus, we see that in the middle of a professional career (work experience from 15 to 25 years) the most pronounced self-attitude indicators are observed. At the same time, one can notice the internal inconsistency of the self-attitude of teachers at this stage: on the one hand, this is the growth of self-confidence, self-acceptance, self-understanding, selfinterest, on the other, self-accusation, which can be interpreted as an increase in the demands placed on oneself.

We used the Mann-Whitney U-test to test for differences in self-attitude levels between the three groups of educators. The calculations were carried out using the computerized statistical package STATISTICA 6.0. The results are shown in Table 3.

Thus, the differences were confirmed on the "self-confidence" scale between samples I and II $(\mathrm{Uemp}=110, \mathrm{p}=0.014)$, I and III (Uemp $=99, \mathrm{p}=0.005)$ and on the "selfunderstanding" scale between groups I and III ( Uemp $=120, \mathrm{p}=0.030)$. 
Table 3. Significance of differences between groups depending on the length of service according to the U-Mann-Whitney criterion.

\begin{tabular}{|l|l|l|l|l|l|l|}
\hline \multirow{3}{*}{ Scales } & \multicolumn{4}{|l}{ Comparison of groups of educators } \\
\cline { 2 - 7 } & I and II & II and III & \multicolumn{2}{l|}{ I and III } \\
\cline { 2 - 7 } & Uemp & R & Uemp & R & Uemp & R \\
\hline 1. self-confidence & 110 & 0.014 & 162 & 0.314 & 99 & 0.005 \\
\hline 2. Attitude of others & 180 & 0.601 & 150 & 0.182 & 165 & 0.354 \\
\hline 3. Self acceptance & 162 & 0.314 & 189 & 0.778 & 181 & 0.620 \\
\hline 4. Self guidance & 147 & 0.157 & 155 & 0.231 & 183 & 0.658 \\
\hline 5. self-blame & 159 & 0.276 & 158 & 0.264 & 196 & 0.925 \\
\hline 6. self-interest & 160 & 0.288 & 161 & 0.301 & 196 & 0.925 \\
\hline 7. self-understanding & 187 & 0.738 & 134.5 & 0.076 & 120 & 0.030 \\
\hline
\end{tabular}

Note: Values with statistically significant differences are in bold.

That is, we can talk about a change in self-confidence during the transition from one stage of professional development to another, as well as an increase in the level of selfunderstanding when reaching the stage of mastery.

In the third stage of the study We determined the level of severity of the emotional burnout syndrome as one of the reasons for the transformation of the gender characteristics of female teachers.

We consider emotional burnout as one of the reasons for the transformation of gender characteristics of women teachers in the process of professional activity. It is one of the types of professional deformation of the teacher's personality and manifests itself in unwillingness to engage in professional activities, in dissatisfaction and indifference towards it.

Therefore, we carried out a methodology for diagnosing the level of emotional burnout of V.V. Boyko.

Of greatest interest to us is the formation of individual phases of emotional burnout in each of the three groups of teachers. The results are shown in Table 4.

Table 4. The severity of the phases of stress development in female teachers with various experience in teaching $(\%)$.

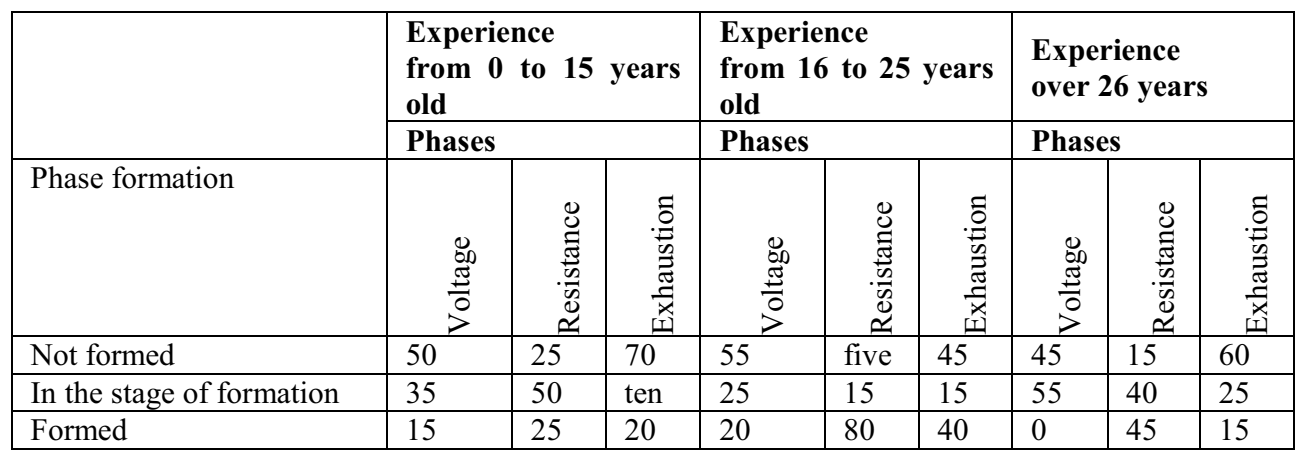

Analyzing the data, we see that the majority of female teachers belonging to the first group, the phases of "stress" and "exhaustion" are not formed. The phase of resistance (resistance to stress) is in the process of formation in 50\% of teachers, which indicates the presence of emotional stress in their professional activities. The formation of the "Tension" (15\%), "Resistance" (25\%) and "Exhaustion" (20\%) phases is observed in a small number of respondents. 
When analyzing this picture, we can see that the majority of respondents have phases "Stress" (55\%) and "Exhaustion" (45\%). And the phase "Resistance" is formed in $80 \%$ of the respondents. This suggests that the majority of teachers of the second group (experience from 16 to 25 years) professional activity causes tension, which they are able to resist.

Analyzing the data obtained, the following can be noted: $45 \%$ of the surveyed female teachers have not formed the "Tension" phase, and 55\% are in the stage of formation. The "Resistance" phase was formed in a large number of respondents (45\%), in a slightly smaller number it is in the process of formation. The absence of the "Exhaustion" phase is observed in $60 \%$ of teachers, and its formation is observed in only a small number $(15 \%)$.

Next, let's see how many (\%) of the surveyed female teachers in each of the three groups have burnout syndrome.

We see that emotional burnout syndrome in the first (experience from 0 to 15 years) and third groups (experience of more than 26 years) is observed in a small number of teachers (10\% each). In the group with experience from 16 to 25 years, emotional burnout occurs much more often $(35 \%)$. Hence, we can conclude that at the beginning of the teacher's professional development the number of stressful situations is not "enough" to form the emotional burnout syndrome (although there are exceptions), while their gradual accumulation occurs, which is manifested at the next stage of professionalization. And upon reaching the stage of mastery, the teacher already learns to cope with stressful situations and react neutrally to many of them. Another reason may be that.

At the fourth stage of the study We determined the differences in the severity of the gender characteristics of the subjects, as well as changes in the severity of the emotional burnout syndrome at different stages of professional activity.

To determine the reliability of differences in the level of professional burnout of women teachers with different length of service, we used Mann-Whitney U-test. The calculations were carried out using the computerized statistical package STATISTICA 6.0. The results obtained are listed in Table 5.

Table 5. Significance of differences in the level of emotional burnout between groups depending on the length of service according to the U-Mann-Whitney criterion.

\begin{tabular}{|l|l|l|l|l|l|}
\hline $\begin{array}{l}\text { Comparisons of groups I } \\
\text { and II }\end{array}$ & $\begin{array}{l}\text { Comparison of II and III } \\
\text { groups }\end{array}$ & $\begin{array}{l}\text { Comparison of groups I and } \\
\text { III }\end{array}$ \\
\hline Uemp & rur. & Uemp & rur. & Uemp & rur. \\
\hline 114 & 0.019 & 153 & 0.210 & 176 & 0.529 \\
\hline
\end{tabular}

Note: Statistically significant differences are in bold.

From the table we see that the differences in the severity of the emotional burnout syndrome are confirmed only between groups I and II. Thus, we can conclude that during the transition from the stage of adaptation to the stage of professionalization, the level of emotional burnout significantly increases.

The severity of burnout syndrome changes along an inverted U-shaped curve, that is, at first there is an increase in the sign, and after it decreases. This can be explained by the fact that upon reaching the stage of professionalization, the teacher has already accumulated a sufficient level of stressful situations (therefore, the level of emotional burnout is high), and by the stage of mastery he will already learn how to cope with them; it may also be due to the leaving of the professional activity of teachers who "burned out" at work, thereby dropping them out and leaving mainly those who can cope with the type of deformation passed.

Then we determined the differences in the severity of the gender characteristics of the subjects with different experience of professional activity. For this, we used one-way analysis of variance (ANOVA), the nonparametric version of which is the H. Kruskal- 
Wallis test. This method allows you to study changes in the effective trait under the influence of changing conditions or gradations of any factor. The calculations were carried out using the computerized statistical package STATISTICA 6.0. We found that the change in masculine traits in female teachers with increasing work experience is random $(\mathrm{F}=$ 725.20 , at $\mathrm{p}=0.000$ ), that is, the hypothesis of our study is partially confirmed, since during the transition from the adaptation stage to the professionalization stage, an increase of the studied trait, and then its decline occurs.

When analyzing the results presented in table 1 , we see that an increase in masculinity occurs when moving from the first to the second group, and then decreases. Thus, we can assume that the hypothesis of our research was confirmed only partially due to the small size of the sample, and also due to the fact that all the respondents are teachers in a school, where, in one way or another, it is necessary to display traits traditionally attributed to women. In addition, it is possible that the reason for the results obtained was that we did not have a real opportunity to conduct a longitudinal study, that is, to trace how the characteristics we studied change in the same subjects with an increase in teaching experience and the transition from one age group to another.

Additionally, we determined the relationship between the severity of gender characteristics in female teachers and the characteristics of their self-attitude, as well as the level of their emotional burnout at different stages of professional activity. We used the rank correlation coefficient rs-Spearman's test. Calculations were made using a computerized statistical packageSTATISTICA 6.0.

Table. Results of correlation analysis by rs-Spearman's test for a group of teachers with experience from 0 to 15 years.

\begin{tabular}{|c|c|c|}
\hline Method name & & V.V. $\quad$ Boyko's \\
\hline $\begin{array}{l}\text { Self-attitude test questionnaire V.V. Stolin, } \\
\text { S.R. Panteleeva (scales) }\end{array}$ & $\begin{array}{l}\text { Femininity Scale from } \\
\text { the Freiburg } \\
\text { Personality } \\
\text { Questionnaire (FPI) }\end{array}$ & $\begin{array}{l}\text { method for } \\
\text { diagnosing the level } \\
\text { of } \quad \text { emotional } \\
\text { burnout }\end{array}$ \\
\hline 1. self-confidence & $0.16(p=0.483)$ & $-0.45(p=0.042) *$ \\
\hline 2. Attitude of others & $-0.11(p=0.626)$ & $0.14(\mathrm{p}=0.545)$ \\
\hline 3. Self acceptance & $-0.18(p=0.435)$ & $-0.01(p=0.951)$ \\
\hline 4. Self guidance & $-0.33(p=0.151)$ & $-0.54(\mathrm{p}=0.012) *$ \\
\hline 5. self-blame & $0.03(\mathrm{p}=0.887)$ & $0.30(\mathrm{p}=0.190)$ \\
\hline 6. self-interest & $0.34(p=0.131)$ & $-0.18(p=0.436)$ \\
\hline 7. self-understanding & $-0.19(p=0.409)$ & $-0.11(p=0.625)$ \\
\hline $\begin{array}{l}\text { The Masculinity-Femininity Scale from the } \\
\text { Freiburg Personality Questionnaire (FPI) }\end{array}$ & & $-0.001(\mathrm{p}=0.993)$ \\
\hline
\end{tabular}

Note: * Indicates characteristics that have a statistically significant correlation.

Based on the data obtained, we can note the presence of a negative correlation in group I between self-confidence and emotional burnout ( $\mathrm{rs}=-0.45, \mathrm{p}=0.042)$, as well as between self-leadership and emotional burnout $(\mathrm{rs}=-0.54, \mathrm{p}=0.012) \ldots$ That is, the more pronounced such characteristics as self-leadership and self-confidence, the less susceptibility of the respondents to emotional burnout. 
Table 7. Results of correlation analysis by rs-Spearman's test for a group of teachers with experience from 16 to 25 years.

\begin{tabular}{|c|c|c|}
\hline Method name & The Masculinity- & V.V. Boyko's \\
\hline $\begin{array}{l}\text { Self-attitude test questionnaire V.V. Stolin, } \\
\text { S.R. Panteleev (scales) }\end{array}$ & $\begin{array}{c}\text { Femininity Scale from } \\
\text { the Freiburg } \\
\text { Personality } \\
\text { Questionnaire (FPI) }\end{array}$ & $\begin{array}{c}\text { method for } \\
\text { diagnosing the level } \\
\text { of emotional } \\
\text { burnout }\end{array}$ \\
\hline 1. self-confidence & $0.17(\mathrm{p}=0.465)$ & $-0.04(\mathrm{p}=0.838)$ \\
\hline 2. Attitude of others & $0.15(\mathrm{p}=0.526)$ & $0.25(\mathrm{p}=0.276)$ \\
\hline 3. Self acceptance & $0.19(\mathrm{p}=0.410)$ & $0.33(\mathrm{p}=0.146)$ \\
\hline 4. Self guidance & $0.08(\mathrm{p}=0.708)$ & $-0.43(\mathrm{p}=0.056)$ \\
\hline 5. self-blame & $-0.33(p=0.143)$ & $-0.26(\mathrm{p}=0.257)$ \\
\hline 6. self-interest & $0.29(\mathrm{p}=0.206)$ & $-0.09(\mathrm{p}=0.700)$ \\
\hline 7. self-understanding & $0.42(\mathrm{p}=0.059)$ & $-0.07(p=0.740)$ \\
\hline $\begin{array}{l}\text { The Masculinity-Femininity Scale from the } \\
\text { Freiburg Personality Questionnaire (FPI) }\end{array}$ & & $0.29(\mathrm{p}=0.203)$ \\
\hline
\end{tabular}

Note: * Indicates characteristics that have a statistically significant correlation.

No correlation was found in the second group of female teachers.

Table 8. Results of correlation analysis by rs-Spearman's test for a group of teachers with over 26 years of experience.

\begin{tabular}{|c|c|c|}
\hline Method name & The Masculinity- & \\
\hline $\begin{array}{l}\text { Self-attitude test questionnaire V.V. Stolin, } \\
\text { S.R. Panteleev (scales) }\end{array}$ & $\begin{array}{l}\text { Femininity Scale from } \\
\text { the Freiburg } \\
\text { Personality } \\
\text { Questionnaire (FPI) }\end{array}$ & 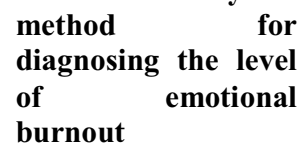 \\
\hline 1. self-confidence & $0.55(\mathrm{p}=0.011) *$ & $-0.43(\mathrm{p}=0.052)$ \\
\hline 2. Attitude of others & $0.44(\mathrm{p}=0.046) *$ & $-0.32(\mathrm{p}=0.157)$ \\
\hline 3. Self acceptance & $0.45(\mathrm{p}=0.043) *$ & $-0.40(\mathrm{p}=0.074)$ \\
\hline 4. Self guidance & $0.41(\mathrm{p}=0.066)$ & $-0.31(\mathrm{p}=0.171)$ \\
\hline 5. self-blame & $-0.15(\mathrm{p}=0.519)$ & $0.18(p=0.427)$ \\
\hline 6. self-interest & $0.35(\mathrm{p}=0.123)$ & $-0.41(\mathrm{p}=0.069)$ \\
\hline 7. self-understanding & $0.54(\mathrm{p}=0.012) *$ & $-0.76(\mathrm{p}=0.000) *$ \\
\hline $\begin{array}{l}\text { The Masculinity-Femininity Scale from the } \\
\text { Freiburg Personality Questionnaire (FPI) }\end{array}$ & & $-0.29(\mathrm{p}=0.212)$ \\
\hline
\end{tabular}

Note: * Indicates characteristics that have a statistically significant correlation.

In the group of teachers with more than 26 years of experience, a positive correlation was found between the results according to the method The scale "Masculinity-femininity" from the Freiburg Personality Questionnaire (FPI) and the following scales from the selfattitude questionnaire of V.V. Stolin, S.R. Panteleev: "self-confidence" ( $\mathrm{rs}=0.55, \mathrm{p}=$ $0.011)$, "attitude of others" ( $r s=0.44, p=0.046)$, "self-acceptance" $(r s=0.45, p=0.043)$ and "self-understanding" ( $\mathrm{rs}=0.54, \mathrm{p}=0.012$ ). Hence, we can conclude that female teachers with feminine traits have pronounced characteristics such as self-confidence, attitude of others, self-acceptance and self-understanding. And also a negative correlation was found between the "self-understanding" scale and the indicator according to the VV Boyko method for diagnosing the level of emotional burnout ( $r s=-0.76, p=0.000)$. This suggests that with a high development of self-understanding, the level of burnout syndrome is minimal.

Thus, our hypothesis is that with an increase in the experience of pedagogical activity among women teachers, an increase in the severity of masculine traits is observed as a result of the study, which was not confirmed; and the hypothesis that with an increase in 
pedagogical work experience among women teachers there is an increase in the level of emotional burnout, it was partially confirmed.

\section{Conclusions}

The study made it possible to draw the following conclusions:

1. Regardless of the length of service in the teaching profession, women of the androgynous type prevail. Women teachers of the feminine type are most often found at the initial stage of mastering the teaching profession in a professional group with less than 15 years of experience and absolutely predominate at the stage of achieving mastery in a group with more than 26 years of teaching experience. In general, women educators with a masculine gender are rare and only in a group with a professional experience of 0 to 15 years. The change in masculine traits in women teachers with increasing work experience is accidental.

2. Self-management and self-acceptance prevail in the self-attitude of women teachers, regardless of the length of their professional activity. The least characteristic quality in all three groups is self-blame. With an increase in the length of the professional activity, selfconfidence and self-acceptance increase.

3. The severity of the emotional burnout syndrome with an increase in experience changes along an inverted U-shaped curve, that is, by the middle of a professional career there is a significant increase in the trait, and in its second half, a decrease, which may be associated with both the achievement of professional skill and the dropout of teachers with burnout syndrome.

Thus, our hypothesis is that with an increase in the experience of pedagogical activity among women teachers, an increase in the severity of masculine traits is observed, has not been confirmed. The hypothesis that with an increase in the pedagogical work experience among women teachers there is an increase in the level of emotional burnout, was partially confirmed.

The hypothesis, which sounded as follows: "with an increase in the experience of pedagogical activity among women teachers, an increase in the severity of masculine traits is observed" as a result of the study, was not confirmed, and the hypothesis "an increase in the pedagogical experience of work among women teachers entails an increase in the level of emotional burnout" partially confirmed. This may be due to the small size of the study group. Another reason could be the fact that we did not have a real opportunity to trace how the studied characteristics change in the same subjects in the course of their professional activities.

\section{References}

8. A.S. Deryabina, Gender approaches in psychological theories and research, Young Scientist, 8 (2), 92-95 (2011)

9. E.P. Ilyinm Gender and Gender, 688 (SPb.: Peter 2010)

10. E.V. Kulaeva, Gender identity in the social self-determination of women, Bulletin of the Kostroma State University. ON THE. Nekrasov, 14 (2), 149-154 (2008)

11. N.L. Ivanova, Self-determination of women with different types of gender, Psychology Questions, 1, 106-115 (2011)

12. T.V. Timchenko, E.V. Danilov, R.R. Khalfina, Gender differences in the manifestation of aggression in adolescents, Bulletin of Psychophysiology, 3, 114-115 (2019) 
13. I.G. Kolmakova, Psychological characteristics and conditions for the development of polyrole behavior of a teacher, 22 (Author's abstract. dis. Cand. psychol. sciences. M.: Psychol. Institute of Russian Acad. education, 2008)

14. A.B. Ostapenko, Gender asymmetry as a consequence of the differentiation of gender roles, Almanac of modern science and education, 1 (44), 122-123 (Tambov: Diploma, 2011).

15. T.V. Kalinina, N.S. Urivskaya, Influence of gender characteristics on the manifestation of aggressive behavior of adolescents. Actual problems of modern pedagogy: materials of the $X$ Intern. Scientific conf., 8-11, https://moluch.ru/conf/ped/archive/212/11928/ (accessed: 04.01.2020) (Samara: LLC ASGARD Publishing House, Samara, March 2017)

16. N.O. Kuznetsova, G.R.Manuylova, R.R. Khalfina, The manifestation of aggressiveness in adolescence in the process of interpersonal communication. Problems of modern teacher education, 57-3, 218-226 (2017)

A. Campbell Sex differences in direct aggression: What are the psychological mediators? Aggression and Violent Behavior, 11, 237-264 (2006)

17. E.M. Gamova, Formation of moral and volitional resistance of adolescents to victimization in a secondary school, 272 (Dissertation research, 2010)

18. N. Karol, The consequences of the school bullying in the representations of students, Universum: Psychology and education, 12(42), 32-36 (2017)

19. K. Rigby, Consequences of bullying in schools, Can J. Psychiatry, 48 (9), 583-59 (2003)

20. V.M. Galuzyak, Smetansky N.I., The problem of personal reference of a teacher, Pedagogy, 3, 36-42 (1998)

21. L.A. Ivashneva, To the question of the teacher's Personality from the position of integral individuality, Pedagogy, 2, 65-72 (2006) 